BJMG 19 (1), 2016 • 95-102

DOI: 10.1515/bjmg-2016-0013

CASE REPORT

\title{
VON RECKLINGHAUSEN DISEASE: ONE PATIENT - VARIOUS PROBLEMS
}

\author{
Bergler-Czop B ${ }^{1, *}$, Miziołek B ${ }^{2}$, Brzezińska-Wcisło L ${ }^{1}$
}

*Corresponding Author: Associate Professor Beata Bergler-Czop, Department of Dermatology, Silesian Medical University Katowice, Francuska Street 20/24, 40-027, Katowice, Poland. Tel./Fax: +48-32-2840877. E-mail: bettina2@tlen.pl

\begin{abstract}
von Recklinghausen disease (vRD), more widely known as neurofibromatosis type 1, belongs to a group of genetic disorders and it is considered to be the most common genodermatosis. The disease has an autosomal dominant pattern of inheritance that involves mutations within the NF1 gene located on chromosome 17 in locus q11.2. The product of the NF1 gene is neurofibromin and the protein is well known to be a tumor suppressor factor. This counteracts possible overactivity of RAS (protein)/MAPK (mitogen-activated protein kinase) and RAS/PI3K/ AKT/ mTOR (phoshatydyloinositol-3-kinase/V-akt murine thy-moma viral oncogene homologue/mammalian target of rapamycin) signaling transduction pathways, preventing from uncontrolled cell proliferation and subsequent tumor formation. A loss of proper functioning of this protein leads to a development of vRD; however, a large variability in a phenotype of the disease and the onset of cutaneous findings, not necessarily in childhood, may provide a clinical diagnosis of the disease late in adulthood. We present a 52-year-old male in whom the diagnosis of VRD was proposed in the sixth decade of life, despite of multiple nodular lesions disseminated over the skin of the whole body and different neurologi-
\end{abstract}

\footnotetext{
${ }^{1}$ School of Medicine in Katowice, Medical University of Silesia in Katowice, Department of Dermatology, Poland

${ }^{2}$ Andrzej Mielęcki Silesian Independent Public Clinical Hospital in Katowice, Department of Dermatology, Poland
}

cal disturbances, not considered for a long time as manifestations of genodermatosis.

Keywords: Neurofibromatosis; Neurofibromin; von Recklinghausen disease (vRD).

\section{INTRODUCTION}

von Recklinghausen disease (vRD), more widely known as neurofibromatosis type 1, belongs to a group of genetic disorders and it is considered to be the most common genodermatosis, with its presumptive incidence estimated at one in 3000 to 5000 births. The disease has an autosomal dominant pattern of inheritance that involves mutations within the NF1 gene located on chromosome 17 in locus q11.2 [1,2]. The product of the NF1 gene is neurofibromin and the protein is well known to be a tumor suppressor factor. This counteracts possible overactivity of RAS (protein)/MAPK (mitogen-activated protein kinase) and RAS/PI3K/AKT/mTOR (phoshatydyloinositol3-kinase/V-akt murine thymoma viral oncogene homologue/mammalian target of rapamycin) signaling transduction pathways, preventing from vuncontrolled cell proliferation and subsequent tumor formation [3]. A loss of proper functioning of this protein leads to a development of $\mathrm{vRD}$, however, a large variability in a phenotype of the disease and the onset of cutaneous findings, not necessarily in childhood, may provide a clinical diagnosis of the disease late in adulthood [4].

Case Presentation. A 52-year-old male patient was admitted to the Department of Dermatology, Silesian Medical University in Katowice, Poland, 


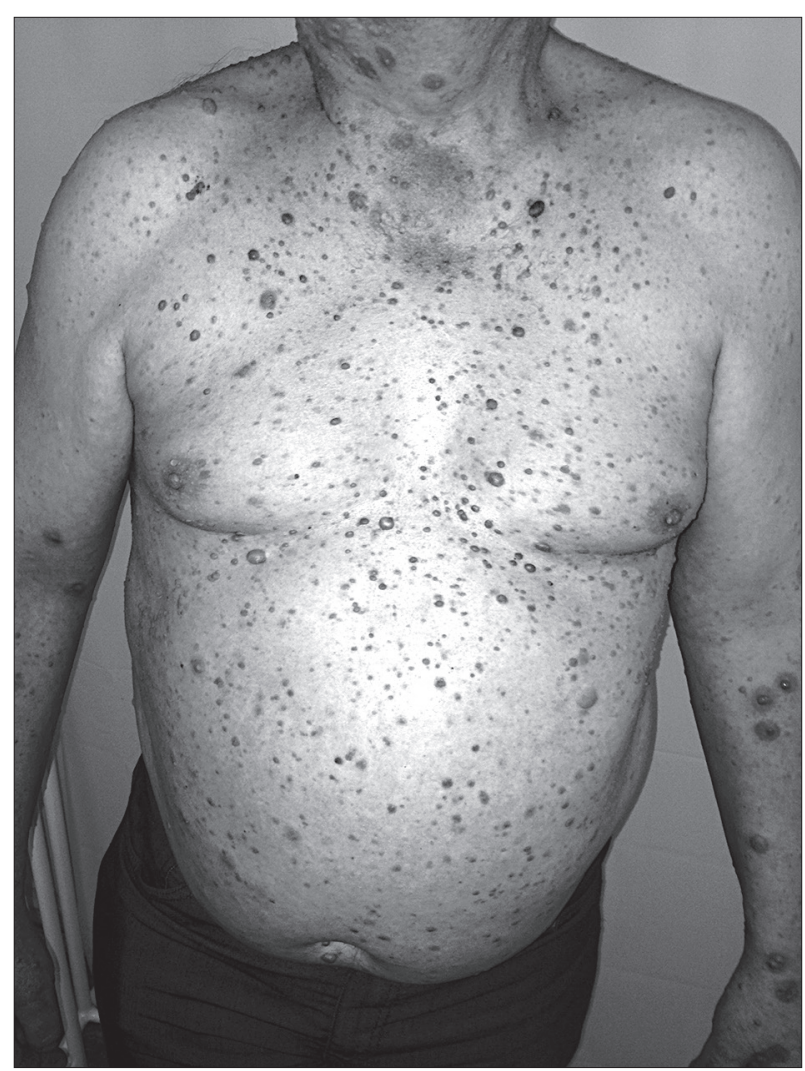

Figure 1. Multiple cutaneous neurofibromas spread over the chest and abdominal surface.

due to multiple nodular lesions disseminated over the skin of the whole body. Those cutaneous findings of skin-like to brown color, were palpable soft, non painful masses with a tendency to be pedunculated (Figures 1 and 2). Previously, those nodular lesions started to appear at puberty, initially affecting the face and then the chest, however, none of these findings had been investigated at that time. Similar, however less numerous, nodular lesions could be found on the skin of arms and the trunk of the patient's mother, but medical investigation had been never expanded and the woman died at the age of 62 years due to a brain tumor.

At the age of 45 , the patient underwent a surgical excision of a rapidly growing tumorous lesion (1.5 $\times 1.5 \mathrm{~cm}$ in size) from the skin of his right forearm and another one $(5.0 \times 4.5 \mathrm{~cm}$ in size $)$ over the right scapula. A histopathology of both lesions provided a diagnosis of neurofibroma. A swelling of the left side of the mandible was the third histopathologically confirmed neurofibroma $(3.0 \times 4 \mathrm{~mm}$ in size $)$, the one detected at a dental consultation at the Department of Dermatology (Figure 3).

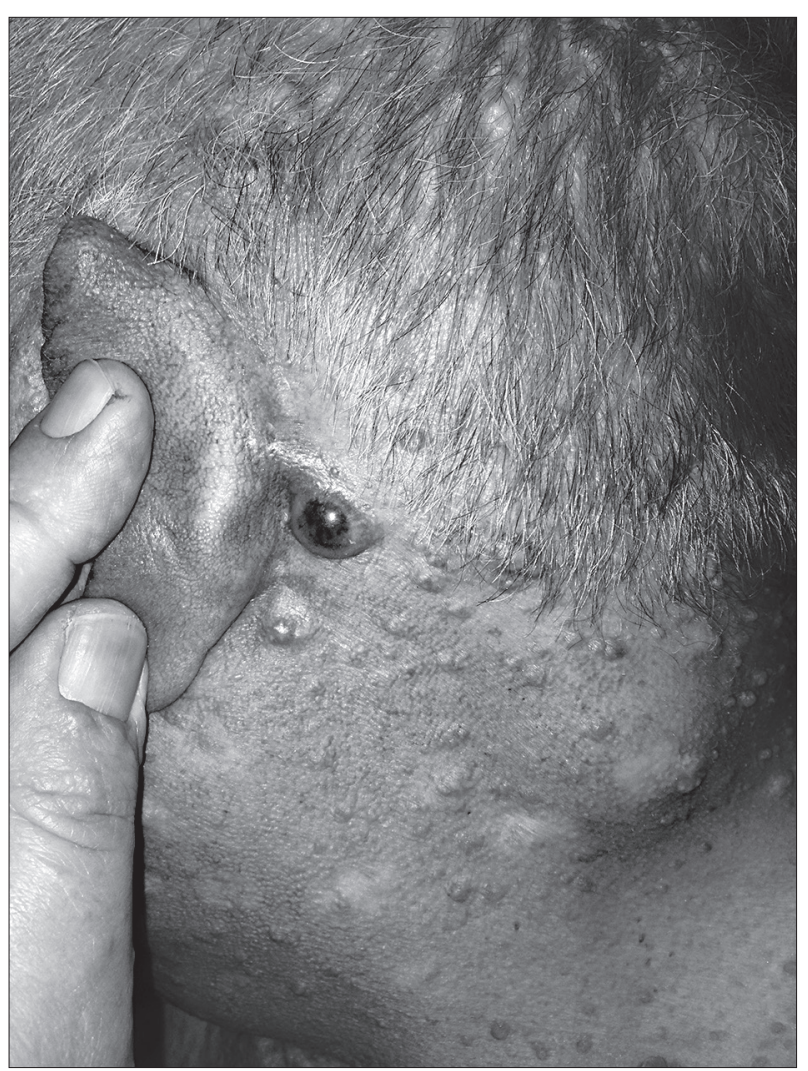

Figure 2. Retroauricular nodular cutaneous neurofibroma.

Retrospectively, in 1984, at the age of 23 , the patient was hospitalized at the Department of Neurology, Katowice, Poland, due to an epileptic seizure. Computed tomography (CT) of the head then revealed a tumor of the pituitary gland, however, the patient refused any surgical treatment of the finding. A series of control CTs, repeated for the following 9 years finally revealed a spontaneous regression of the tumor within the sella turica in 1993. Unfortunately, CTs taken in recent years (2010-2014) revealed a displacement of the cerebellar tonsils into the foramen magnum (Figure 4) and some edema of the optical chiasma. Ultrasonography of the right eyeball confirmed a focal distention ( $9.1 \mathrm{~mm}$ width) of the optic nerve within the orbital part providing a suspicion of optic glioma with no further enlargement of this finding at follow-up. Additionally, a consultation of the ophthalmologist at the Department of Dermatology revealed a presence of two nodular lesions on the right iris (presumptively Lisch nodules). Despite of detected abnormalities, no surgical treatment was required since the patient was in relatively good clinical condition (without headaches or strabismus) 


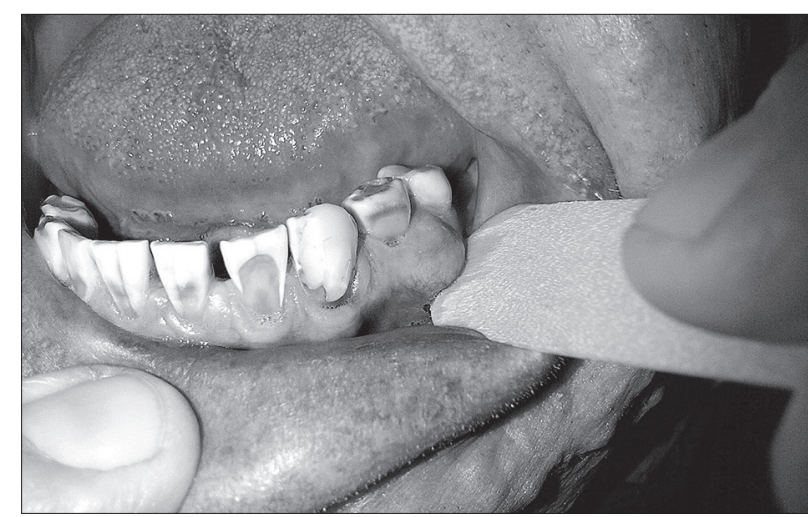

Figure 3. Swelling of the mandible detected at dental consultation.

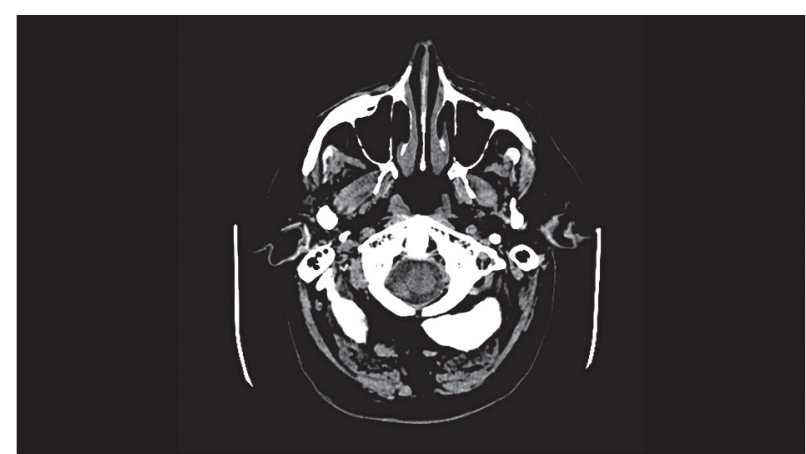

Figure 4. Computer tomography of the head: a displacement of the cerebellar tonsils into the foramen magnum.

and surprisingly, his epilepsy was well controlled by pharmacological agents (Gabapentin $600 \mathrm{mg}$ administered twice daily and Carbamazepine $400 \mathrm{mg}$ three times daily).

An evident abnormality in the patient's posture was a severe developmental scoliosis and deformity of the left ankle (Figure 5). An X-ray of the left shin revealed a significant loss of cortical bone close to the central part of the left fibula, with an abscence of its distal part and replaced by a metal implant. Retrospectively, the patient had undergone a surgical treatment of bone deformity of the left shin in his early childhood, however, persistent impairment of mobility was evident by a severe limping at the walk.

Interestingly, despite characteristic histopathology of excised cutaneous lesions and concomitant neurological disturbances, no investigation of genodermatosis was previously performed. The entire spectrum of abnormalities provided a clinical diagnosis of $\mathrm{VRD}$ based on criteria of recognition established at the National Institutes of Health Consensus Conference in 1988. At the Department of Dermatol-

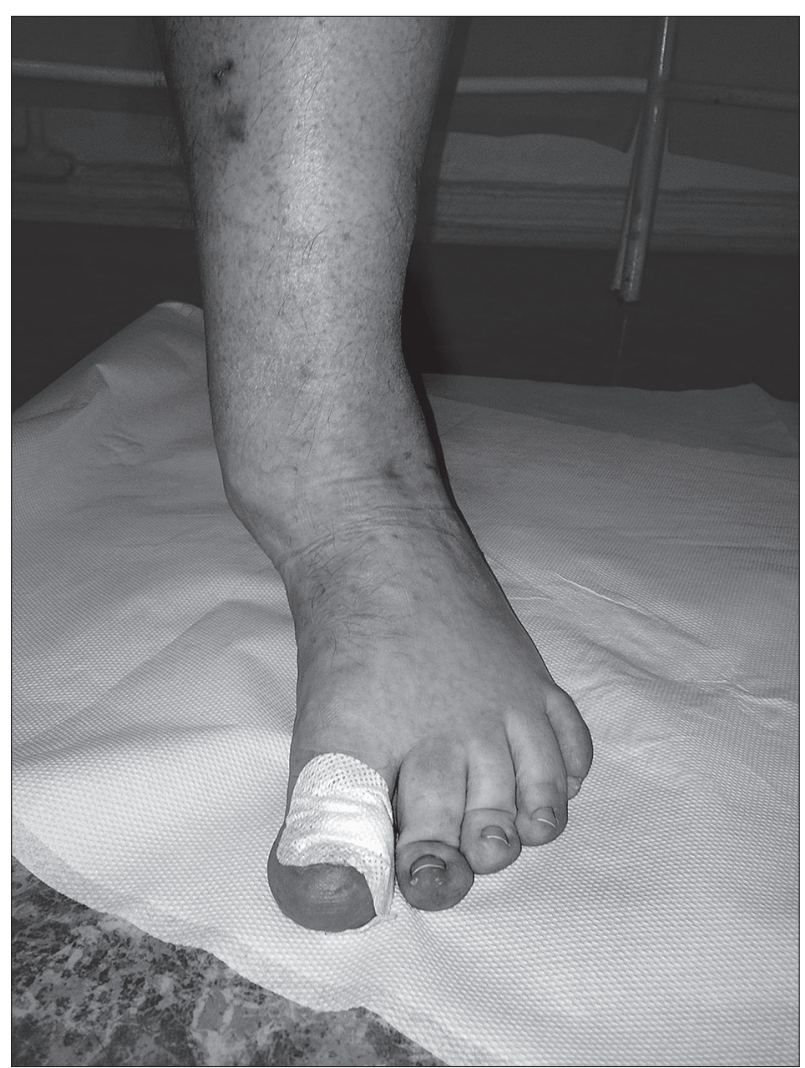

Figure 5. Deformity of the left ankle.

ogy, the patient was referred for further treatment of the most disfiguring skin findings with cryotherapy.

\section{DISCUSSION}

von Recklinghausen disease belongs to a group of disorders called phakomatosis, which is characterized by a set of symptoms resulting from the involvement of the skin, nervous system and eye. However, there are many possible manifestations of vRD [1].

The disease is a consequence of a mutation within the NF1 gene located on chromosome 17 in locus q11.2. An autosomal dominant pattern of inheritance is a characteristic feature of the disease, however, it is observed that about $50.0 \%$ of affected patients do not have a family history of the disease $[1,5,6]$. Sporadic $\mathrm{VRD}$ was speculated to occur as a new mutation mainly in the germ cells of fathers. Opinions about an influence of parental age on the risk of occurrence of $N F 1$ in a child are divergent. Although Bunin et al. [7] observed that fathers of patients with vRD were 1.5 years older than fathers of control subjects at the 
birth of the child, the difference was only borderline statistically significant.

The product of the NF1 gene is a cytoplasmic $327 \mathrm{kDa}$ protein called neurofibromin, which acts predominantly as tumor suppressor factor. Neurofibromin modulates the activity of another protein called RAS which is responsible for regulation of cell proliferation and differentiation acting through RAS/MAPK and RAS/PI3K/AKT/mTOR signaling transduction pathways $[3,8]$. Briefly, both pathways mediate a signal from a membrane tyrosine kinase receptor activated by growth factor. The activation of such receptor promotes an activation of RAS protein by binding a GTP (guanosine triphosphate) particle to this protein that leads to a formation of activated RAS-GTP complex. This complex subsequently activates the following pathways dependant on MAPK and/or PI3K/AKT/mTOR. Both pathways provide a signal to the nucleus for cellular growth and proliferation [9].

Neurofibromin converts active RAS-GTP into its inactive form, thereby inhibiting both downstream pathways (MAPK and PI3K/AKT/mTOR). Preserved activity of neurofibromin limits possible overstimulation by these pathways preventing from an excessive growth and proliferation of cells. Mutations within the NF1 gene impair functions of neurofibromin that cannot properly control the activity of RAS and, therefore, also of both downstream pathways. Possible concomitant activating mutations, which convert the RAS proto-oncogene into an oncogene, develop a condition that can lead to uncontrolled cell proliferation with further tumor formation [10]. Most patients carry (in all their cells) both normal and dysfunctional copies of the NF1 gene. In accordance with Knudson's two-hit hypothesis, vRD patients carrying a heterozygous germline mutation within the $N F 1$ gene develop neurofibromas if mutation occurs also in the second, wild-type, NF1 allele. Somatic inactivation of the NF1 gene may result from different mutational mechanisms and may involve intragenic mutations, loss of heterozygosity $(\mathrm{LOH})$ and epigenetic modification of the promoter region. Biallelic inactivation of the NF1 gene, causing a complete loss of functional neurofibromin, initiates the pathogenic process that eventually results in the formation of tumors. The NF1 gene inactivation may occur through by relatively subtle mutation that can affect just a few DNA bases, or may involve large genomic changes affecting large chromosomal regions with contiguous genes, or even the entire chromosome 17 [8].

Regarding to the type and the extent of mutation within the $N F 1$ gene, a different phenotype can be developed. Approximately $5.0-20.0 \%$ of all vRD patients carry a heterozygous deletion of usually 1.5 $\mathrm{Mb}$, involving the $N F 1$ gene and contiguous genes lying in its flanking regions. The loss of other genes, as well as NF1 haploinsufficiency, is responsible for more severe than usual phenotypes known as vRD microdeletion syndrome. This condition is characterized by earlier onset of classic manifestations of vRD, additionally complicated by a development of other pathologies such as dysmorphisms, cardiac anomalies, mental retardation or greater risk of malignancies [11,12]. Another observations revealed an association between mutations at the $5^{\prime}$ end of the NF1 gene and the development of optic glioma in patients with vRD [13]. Upadhyaya et al. [14] and Rojnueangnit et al. [15] found that a 3 bp deletion (c.2970-2972delAAT) in exon 17, causing Met992del in neurofibromin protein, was responsible for a development of phenotype without cutaneous the neurofibromin. Pinna et al. [16] presented another mild variant of $\mathrm{VRD}$, also related to a missense mutation affecting codon 1809 (c.5425C $>\mathrm{T}$ ) and causing a substitution of arginine to cysteine (Arg1809Cys) in neurofibromin. Characteristics for these phenotypes was an absence of the following abnormalities: cutaneous neurofibromas, Lisch nodules, typical osseous lesions or symptomatic optic gliomas. In accordance with observations by Rojnueangnit et al. [15], this variant was also associated with a short stature and features suggesting Noonan syndrome [16].

Theoretically, substitution of a single nucleotide of the Arg 1809 codon CGC can result in six different missense variants. Arg 1809 resides at the $\mathrm{C}$-terminal $\alpha$ helix of the Pleckstrin Homology (PH) domain of neurofibromin, however, its functions have not been fully elucidated [15]. Presumptively, the domain interacts with the Sec-14 domain, thus targeting neurofibromin to facilitate colonization with RAS [17]. Amino acid changes at position 1809 were found to cause a significant rearrangement of the secondary structure of the $\mathrm{PH}$ domain that severely disrupt interactions between the above reported domains within the protein. The presence of only cutaneous pigmentary manifestations of rVD would be deprived 
of cutaneous neofibromas or Lisch nodules, with a special tendency to occurrence of dysmorphic features characteristic for the Noonan Syndrome [18].

The diagnosis of $\mathrm{VRD}$ is based on clinical criteria and genetic analysis is not required. To recognize the disease, it is necessary to fulfill at least two out of seven following criteria established at the National Institutes of Health Consensus Conference in 1988 $[1,19,20]: 1) \geq 6$ CAL (café au lait) spots $(>5 \mathrm{~mm}$ in size at pre-puberty and $>15 \mathrm{~mm}$ in adults); 2) axillary or groin freckling (Crowe's symptom ); 3 ) $\geq 2$ neurofibromas of any type or one plexiform neurofibromas; 4) optic pathway glioma; 5) a presence of $\geq 2$ Lisch nodules (iris hamartomas, best observed in a slit lamp); 6) detection of characteristics for vRD bone abnormalities (bony dysplasia of the sphenoid wing; thinning of the long bone cortex with or without pseudarthrosis of the long bones); 7) first degree relative with vRD.

Our male patient fulfilled four of these seven criteria: multiple neurofibromas, freckles in axillary areas, Lisch nodules and the presence of bone abnormalities within the left shin. Another suspicious findings could enhance the clinical diagnosis of $\mathrm{VRD}$ : presumptive $\mathrm{VRD}$ of the patient's mother, a suspicion of the right optic glioma and spotty hyperpigmentations of the skin. Interestingly, patients with vRD may experience CAL spots for a period of time, with the onset of such lesions usually in early childhood. Their numbers tend to increase into the early teens and then CAL spots may fade or even disappear in some adults $[1,5]$.

The majority of patients with $\mathrm{vRD}$ can be diagnosed by careful analysis of clinical symptoms of the disease. Recommendations for considering $N F 1$ gene testing involve [5]: 1) young children with $\geq 6 \mathrm{CAL}$ spots as the sole disease manifestation with negative family history towards $\mathrm{VRD}$ - other features (including cutaneous neurofibromas) may not develop until early adulthood; 2) children over 3 years old with 3-5 CAL spots and no other manifestations of Vrd; 3) families with CAL patches and freckling but without neurofibromas - unusual phenotypes of the disease.

Indeed, some clinical variants may provide difficulties in proper diagnosis and recently, KehrerSawatzki [17], inspired by Rojnueangnit et al. [15], postulated the importance of mutation testing in $\mathrm{VRD}$ patients. This management would allow for a proper recognition of less evident cases involving the above mentioned phenotypic variants. Such genetic analysis can also provide great psychological relief to those patients with the above presented clinical variants of the disease due to the absence of the greater risk of vRD-associated tumors [15,17]. Santoro et al. [18] also advised the necessity of combined vRD testing together with SPRED1 (sprouty-related, EVH1 domain containing protein 1) analysis. Essentially, mutations of the SPRED1 gene lead to the development of Legius syndrome, which is a disorder with a pigmentary phenotype overlapping with vRD syndrome, but with a much better long-term prognosis [21]. Molecular analysis of the NF1 gene based on genomic DNA is challenging due to its large size (more than 50 exons and $300 \mathrm{~kb}$ of genomic sequence), as well as the presence of NF1 pseudogenes on the other chromosomes [22]. Abramowicz and Gos [3] suggested combining several methods to analyze the NF1 gene that allows the detection of mutations in up to $95.0 \%$ of patients with a clinical diagnosis of the disease. There is a superiority of multiplex ligation-dependent probe amplification (MLPA) over fluorescent in situ hybridization (FISH). Multiplex ligation-dependent probe amplification allows for both quantitative assessment of specific DNA fragments, as well as for detection of duplications or deletions (even of a single exon) within the NF1 gene. In contrast to MLPA, FISH detects mainly deletions involving large portions of the NF1 gene, and furthermore, there is a risk of hybridization of the probe to false NF1 pseudogenes. Another inadequate technique for analysis used to be the protein truncation test. Undoubtedly, a very useful technique comprises sequencing of the $N F 1$ gene based on the analysis of cDNA synthesized by reverse transcription from mRNA. This analyzes only a small portion of the NFl gene without its introns. This technique was estimated to detect approximately $90.0 \%$ of mutations in patients with a clinical diagnosis of vRD. However, some doubts result from a fact that a large number of the $N F 1$ genes involve splicing abnormalities, and therefore, it is more reasonable to combine sequencing based on both mRNA and genomic DNA [4].

Treatment of vRD has still been only a symptomatic striving for reduction of the most disfiguring or life-threatening complications of the disease. Plexiform neurofibromas, tumors pressing peripheral nerves or those causing other neurological symptoms and suspected malignancies, should be referred for 
mandatory surgical treatment. Repeated removal of disfiguring cutaneous lesions with cryo-surgery or laser therapy may significantly improve individual quality of life, allowing for achievement of selfacceptance [1].

\section{CONCLUSIONS}

We present a case of NF-1 in the patient, who despite the typical course and appearance of the skin changes, and a positive family history, has not been informed about the likely diagnosis of a genetic syndrome and its resulting consequences.

Declaration of Interest. The authors report no conflicts of interest. The authors alone are responsible for the content and writing of this article.

\section{REFERENCES}

1. Braun-Falco O, Plewig G, Wolff HH, Burgdorf WHC. Fakomatozy. In: Braun-Falco O, Plewig G, Wolff HH, Burgdorf WHC, Eds. Dermatologia. Lublin, Poland: Czelej. 2002; 793-797.

2. Sabol Z, Kipke-Sabol L. Neurofibromatosis type 1 (von Recklinghausen disease or peripheral neurofibromatosis): From phenotype to gene. Lijec Vjesn. 2005; 127(11-12): 303-311.

3. Abramowicz A, Gos M. Neurofibromin in neurofi-bromatosis type 1 - Mutations in NF1gene as a cause of disease. Dev Period Med. 2014; 18(3): 297-306.

4. Shofty B, Constantini S, Ben-Shachar S. Advances in molecular diagnosis of neurofibromatosis type 1. Semin Pediatr Neurol. 2015; 22(4): 234-239.

5. Ferner RE. Neurofibromatosis 1. In: Ferner RE, Huson SM, Evans DGR, Eds. Neurofibromatoses in Clinical Practice. London, UK: SpringerVerlag. 2011; 27-30.

6. Rasmussen S, Friedman JM. NF1 gene and neurofi-bromatosis 1. Am J Epidemiol. 2000; 151(1): 33-40.

7. Bunin GR, Needle M, Riccardi VM. Paternal age and sporadic neurofibromatosis 1: A case-control study and consideration of the methodologic issues. Genet Epidemiol. 1997; 14(5): 1507-1516.
8. Laycock-van Spyk S, Thomas N, Cooper DN, Upadhyaya M. Neurofibromatosis type 1-associated tumours: Their somatic mutational spectrum and pathogenesis. Hum Genomics. 2011; 5(6): 623-690.

9. Yap YS, McPherson JR, Ong CK, Rozen SG, Teh BT, Lee AS, et al. The NF1 gene revisitedFrom bench to bedside. Oncotarget. 2014; 5(15): 5873-5892.

10. Brems H, Beert E, de Ravel T, Legius E. Mechanisms in the pathogenesis of malignant tumours in neurofibromatosis type 1. Lancet Oncol. 2009; 10(5): 508-515.

11. Venturin M, Guarnieri P, Natacci F, Stabile M, Tenconi R, Clementi M, et al. Mental retardation and cardiovascular malformations in NF1 microdeleted patients point to candidate genes in 17q11.2. J Med Genet. 2004; 41(1): 35-41.

12. Pasmant E, de Saint-Trivier A, Laurendeau I, Dieux-Coeslier A, Parfait B, Vidaud M, et al. Characterization of a 7.6-Mb germline deletion encompassing the NF1 locus and about a hundred genes in an NF1 contiguous gene syndrome patient. Eur J Hum Genet. 2008; 16(12): 1459-1466.

13 Sharif S, Upadhyaya M, Ferner R, Majounie E, Shenton A, Baser M, et al. A molecular analysis of individuals with neurofibromatosis type 1 (NF1) and optic pathway gliomas (OPGs), and an assessment of genotype-phenotype correlations. J Med Genet. 2011; 48(4): 256-260.

14. Upadhyaya M, Huson SM, Davies M, Thomas N, Chuzhanova N, Giovannini S, et al. An absence of cutaneous neurofibromas associated with a 3-bp inframe deletion in exon 17 of the NF1 gene (c.2970-2972delAAT): evidence of a clinically significant NF1 genotype-phenotype correlation. Am J Hum Genet. 2007; 80(1): 140-151.

15. Rojnueangnit K, Xie J, Gomes A, Sharp A, Callens T, Chen Y, et al. High incidence of Noonan syndrome features including short stature and pulmonic stenosis in patients carrying NF1 missense mutations affecting p.Arg 1809: Genotype-phenotype correlation. Hum Mutat. 2015; 36(11): 1052-1063.

16. Pinna V, Lanari V, Daniele P, Consoli F, Agolini E, Margiotti K, et al. p.Arg1809Cys Substitution in neu-rofibromin is associated with a distinctive 
NF1 phenotype without neurofibromas. Eur J Hum Genet. 2015; 23(8): 1068-1071.

17. Kehrer-Sawatzki H. Neurofibromatosis type 1 without neurofibromas: Genotype-phenotype correlations in NF1. Hum Mutat. 2015; 36(11): doi: 10.1002/humu. 22669.

18. Santoro C, Maietta A, Giugliano T, Melis D, Perrotta S, Nigro V, et al. Arg(1809) Substitution in neurofibromin: Further evidence of a genotypephenotype correlation in neurofibromatosis type 1. Eur J Hum Genet. 2015; 23(11): 1460-1461.

19. Bayliss S, Mallory F, Bree A, Chern P. Dermatologia pediatryczna. In: Bayliss S, Mallory F,
Bree A, Chern P, Eds. Diagnostyka i Leczenie. Lublin, Poland: Czelej. 2007; 387-389.

20. Baran E. Nowotwory skóry, klinika, patologia, leczenie. In: Baran E, Ed. Łódź, Poland: Galaktyka. 2008; 195-197.

21. Sumner K, Crockett DK, Muram T, Mallempati $\mathrm{K}$, Best H, Mao R. The SPRED1 variants repository for Legius syndrome. G3 (Bethesda). 2011; 1(6): 451-456.

22. Lodish MB, Stratakis CA. Endocrine tumours in neurofibromatosis type 1 , tuberous sclerosis and related syndromes. Best Pract Res Clin Endocrinol Metab. 2010; 24(3): 439-449. 
